\title{
BioOne enesencen

\section{Natural Transmission of Dengue Virus by Aedes albopictus at Monterrey, Northeastern Mexico}

Author(s): Olga S. Sanchez-Rodríguez, Rosa M. Sanchez-Casas, Maricela Laguna-Aguilar, Marcela S. Alvarado-Moreno, Ewry A. Zarate-Nahon, Rocio Ramirez-Jimenez, Carlos E. Medina de la Garza, Raul Torres-Zapata, Marco Dominguez-Galera, Pedro MisAvila and Ildefonso Fernandez-Salas

Source: Southwestern Entomologist, 39(3):459-468. 2014.

Published By: Society of Southwestern Entomologists

DOI: http://dx.doi.org/10.3958/059.039.0307

URL: http://www.bioone.org/doi/full/10.3958/059.039.0307

BioOne (www.bioone.org) is a nonprofit, online aggregation of core research in the biological, ecological, and environmental sciences. BioOne provides a sustainable online platform for over 170 journals and books published by nonprofit societies, associations, museums, institutions, and presses.

Your use of this PDF, the BioOne Web site, and all posted and associated content indicates your acceptance of BioOne's Terms of Use, available at www.bioone.org/page/terms_of use.

Usage of BioOne content is strictly limited to personal, educational, and non-commercial use. Commercial inquiries or rights and permissions Bio pequests should beodireeted toin the indilividutal publishier as teopyrighe hioldethors, nonprofit publishers, academic institutions, research libraries, and research funders in the common goal of maximizing access to critical research. 


\title{
Natural Transmission of Dengue Virus by Aedes albopictus at Monterrey, Northeastern Mexico
}

\author{
Olga S. Sanchez-Rodríguez ${ }^{1}$, Rosa M. Sanchez-Casas ${ }^{4,5}$, \\ Maricela Laguna-Aguilar², Marcela S. Alvarado-Moreno ${ }^{1}$, Ewry A. Zarate-Nahon ${ }^{3}$, \\ Rocio Ramirez-Jimenez ${ }^{3}$, Carlos E. Medina de la Garza ${ }^{5}$, Raul Torres-Zapata ${ }^{1}$, \\ Marco Dominguez-Galera², Pedro Mis-Avila², and Ildefonso Fernandez-Salas 1,5,6
}

\begin{abstract}
Dengue cases occur frequently at Nuevo Leon, Mexico, where Aedes aegypti (L.) and Ae. albopictus (Skuse) are present. Ae. albopictus is considered the second vector of dengue. Because it bites humans outdoors during the day, the mosquito plays an important role in transmission of dengue virus (DENV). However, no previous studies at Nuevo Leon indicated the role of the mosquito outdoors. To assess Ae. albopictus for dengue virus, mosquitoes were collected from April to October 2010 at five localities at Guadalupe and Santiago, Nuevo Leon, (Northeast) Mexico, by using two methods: engine backpack aspirator and ovitraps. In total, 1,836 Ae. albopictus and $833 \mathrm{Ae}$. aegypti mosquitoes were collected by ovitrap and engine backpack aspirator methods. Groups of mosquitoes were processed by RT-PCR. Examination for DENV infection of mosquitoes showed one positive group of four female Ae. albopictus from an ovitrap. This research provided information that showed transovarial transmission of dengue virus in Ae. albopictus occurred naturally, maintaining endemic levels of disease at a study site.
\end{abstract}

\section{Introduction}

Dengue virus (DENV) is the most important mosquito-borne viral disease of humans in the world (WHO 2009). Approximately 2.5 billion people are at risk for infection. Dengue is caused by one of four related, but antigenically distinct (Gubler 1988) serotypes (DENV 1-4) and is transmitted mostly by Aedes aegypti (L.) and Ae. albopictus (Skuse) mosquitoes (Hawley 1988).

Ae. aegypti is the principal vector of the disease in Mexico (Garcia-Rejon et al. 2008). Ae. albopictus near the Mexico-USA border were first identified in 1988 at Matamoros City. After more than two decades, Ae. albopictus has been reported

\footnotetext{
${ }^{1}$ Universidad Autonoma de Nuevo Leon, Facultad de Ciencias Biologicas, Laboratorio de Entomologia Medica, San Nicolas de los Garza, Nuevo Leon, Mexico.

${ }^{2}$ Secretaria de Salud del Estado de Quintana Roo, Cancun, Quintana Roo.

${ }^{3}$ Universidad Autónoma de Guerrero, Centro de Investigación de Enfermedades Tropicales, Acapulco, Guerrero, Mexico.

${ }^{4}$ Universidad Autonoma de Nuevo Leon, Facultad de Medicina Veterinaria y Zootecnia, Escobedo, Nuevo Leon, Mexico.

${ }^{5}$ Universidad Autonoma de Nuevo Leon, Centro de Investigacion y Desarrollo en Ciencias de la Salud, Unidad de Patogenos Emergentes, Monterrey, Nuevo Leon, Mexico.

${ }^{6}$ Instituto Nacional de Salud Publica, Centro Regional de Investigacion en Salud Publica, Tapachula, Chiapas, Mexico.
} 
throughout Mexico. Ibañez-Bernal and Martinez-Campos (1994) documented finding the species in Coahuila and Veracruz States, Casas-Martinez and TorresEstrada (2003) found it in Chiapas, southern Mexico, and Salomon-Grajales et al. (2012) found it in a cemetery on the Yucatan Peninsula.

Analysis of the ecology of larvae in Nuevo Leon and Coahuila states showed an overlap of $A e$. albopictus with similar Ae. aegypti breeding sites in the home (Rodriguez-Tovar and Ortega-Martinez 1994, Orta-Pesina et al. 2001). The behavior was expected because in Southeast Asia, Ae. albopictus is known as a vector adapted to different environmental conditions. Like Ae. aegypti, it is adapted to the peridomestic environment where it feeds on humans and other animals (Hawley 1988). Ae. albopictus eggs can resist desiccation for several months. Besides natural containers, such as tree holes, plant axils, cut bamboo stumps, and opened coconuts, which constituted the original larval habitats of the species, Ae. albopictus larvae use outdoor artificial containers such as water-storage barrels and trash receptacles (Gubler and Kuno 1997).

Ae. albopictus was first implicated as a vector of dengue in the Philippines in 1926 (Siler et al. 1926). Later it was reported that the vector was susceptible to oral infection by all four serotypes compared to Ae. aegypti (Rudnick and Chan 1965). Vertical transmission was demonstrated in the genital chamber of the female as mature eggs were fertilized during oviposition (Rosen 1988). The importance of transovarial transmission of dengue virus in nature enables knowing how the virus is maintained during interepidemic periods. Vertical transmission of dengue has been experimentally demonstrated in Ae. albopictus (Rosen et al. 1985, Mitchell and Miller 1990). However, the role of the species as an active DENV transmitter in the New World is poorly documented.

Many Ae. albopictus mosquitoes were collected in the field during DENV outbreaks, providing circumstantial evidence that the species might contribute to the DENV-transmission cycle. Ae. albopictus were more abundant than Ae. aegypti during an outbreak in Hawaii in 2001-2001 (Effler et al. 2005). Similarly, an autochthonous dengue outbreak at Key West, FL, in 2010 incriminated Ae. aegypti mosquitoes with vectoring DENV (MMWR 2010), despite Ae. albopictus being found at the location (O'Meara at al. 1995). In the outbreak in Puerto Rice in 2010 which resulted in 21,000 cases of dengue (CDC 2010), Ae. albopictus were frequently trapped in the field. The role of Ae. albopictus in these outbreaks was not assessed. The only report of natural field infection by DENV of Ae. albopictus in the Americas was at Reynosa City, a city bordering Texas. Ibañez-Bernal et al. (1997) isolated DENV 2 and DENV 3 from 10 mosquito males. Periodic outbreaks of dengue occur in northeastern states of Mexico. Although Ae. aegypti is recognized as the main vector in the area, Ae. albopictus are increasing in number and invading suburban and rural localities. This study was aimed at determining the epidemiological significance in transmission of dengue viruses by suburban $A e$. albopictus near the metropolitan area of Monterrey, northeastern Mexico.

\section{Materials and Methods}

Study Sites. Field work was done from 30 April to 23 October 2010 at Santiago $\left(25^{\circ} 24^{\prime} 59.95^{\prime \prime} \mathrm{N}, 1^{\circ} 00^{\circ} 09^{\prime} 32.83^{\prime \prime} \mathrm{O}\right)$ and Guadalupe $\left(25^{\circ} 41^{\prime} 03.24{ }^{\prime \prime} \mathrm{N}\right.$, $\left.100^{\circ} 15^{\prime} 03.78^{\prime \prime O}\right)$ near of the metropolitan Monterrey City area. Locations were chosen based on abundant mosquitoes, the presence of Ae. albopictus, and reported cases of dengue (Orta-Pesina et al. 2005). Santiago is south of 
Monterrey, capital city of Nuevo Leon. Santiago has a population of slightly more than 40,000 people (INEGI 2010), and $59 \%$ of the area is forested, $9 \%$ is dedicated to agriculture, and only 1\% is urban (Key 19049, 2009). Guadalupe is $20 \mathrm{~km}$ north of Santiago; it covers $0.09 \%$ of the surface of Nuevo Leon, with a total population of 678,006 (INEGI 2010). At Guadalupe, $50 \%$ of the area is urban, $1 \%$ is dedicated to agriculture, $36 \%$ corresponds to forests and bushes, and $1 \%$ is pastureland (Key 19026, 2009). Four sampling locations were selected at Santiago: Antonio Villalon, $\left(25^{\circ} 23^{\prime} 58.70^{\prime \prime} \mathrm{N}, 100^{\circ} 07^{\prime} 28.06^{\prime \prime} \mathrm{O}\right)$, a suburban residential zone; a food touristic area that has all the necessary characteristics for biting activity; Mahuacates $\left(25^{\circ} 24^{\prime} 43.21^{\prime \prime} \mathrm{N}, 100^{\circ} 10^{\prime} 20.78^{\prime \prime} \mathrm{O}\right)$; and the Cemetery at San Marco. Only Rincon de la Sierra $\left(25^{\circ} 38^{\prime} 16.07^{\prime \prime} \mathrm{N}, 100^{\circ} 11^{\prime} 59.08^{\prime \prime O}\right)$, a foothill and forested residential settlement, was selected at Guadalupe. Dengue fever is consistently endemic at both sites although more cases always are reported from Guadalupe. In 2012, Guadalupe registered 305 cases of dengue fever and 43 of dengue hemorrhagic fever while Santiago reported 21 cases of dengue fever and two of dengue hemorrhagic fever (Secretaria de Salud NL 2012).

Collection of Eggs in Ovitraps. One hundred black plastic 500-ml ovitraps were placed at each of the following sites: Antonio Villalon, San Marco cemetery, Mahuacates, and Rincon de la Sierra, but in the food area only 20 ovitraps were placed to collect eggs from Ae. albopictus and Ae. aegypti. Ovitraps were filled to two-thirds with tap water, and a strip of filter paper was placed inside. Two to four ovitraps per premise were placed in shaded places in backyards of houses, and trees, vegetative areas, plant pots, and gardens of the cemetery. After 5 days, the artificial breeding sites were checked for oviposition by Aedes mosquitoes. Filter paper stripes were removed and transported to hatch eggs and rear adult mosquitoes at the insectary of the Medical Entomology Laboratory at the University of Nuevo Leon (Perez et al. 2004). A chill table (BioQuip, CA) was used while counting the eggs collected and identifying emerged adults by using a taxonomic key (Darsie and Ward 2005) to Aedes species. Groups of a maximum of 25 mosquitoes by species, sex, location, and date were put into 2.5-ml Eppendorf tubes and stored at $-80^{\circ} \mathrm{C}$ for molecular identification of DENV.

Collection of Adult Mosquitoes. Ae. albopictus and Ae. aegypti mosquitoes were collected using an engine backpack aspirator (Clark and Gubler 1994). Sampling was at outdoor locations of the same study sites. Documented resting areas such as vegetation and other natural points were targeted because of the biology of the species (Hawley 1988). Adult mosquitoes were transported in dry ice to the Medical Entomology Laboratory at the University of Nuevo Leon, Mexico. A chill table was used while identifying the mosquitoes by taxonomic keys (Darsie and Ward 2005) and separating them into groups by species, sex, location, and date collected. Groups of a maximum of 25 mosquitoes were stored at $-80^{\circ} \mathrm{C}$ for molecular identification of DENV.

Molecular Identification of DENV in Egg-reared and Resting Adult Ae. albopictus and Ae. aegypti Males and Females. Groups of Aedes species were processed for DENV identification by RT-PCR. Mosquitoes in Eppendorf tubes were triturated using a Tissue Ruptor (QIAGEN, Valencia, CA) and $0.6 \mathrm{ml}$ of cold minimum essential medium (GIBCO BRL) containing $2 \%$ fetal bovine serum (GIBCO BRL). The resulting suspension was added to a QIA shredder column (QIAGEN), and the columns were centrifuged at $14,000 \mathrm{rpm}$ for 3 minutes at $4^{\circ} \mathrm{C}$. The supernatant was separated into two, $300 \mu \mathrm{l}$ Eppendorf tubes for RNA extraction, and the remaining suspensions were stored at $-80^{\circ} \mathrm{C}$. Virus RNA was 
extracted using an RNeasy kit (QIAGEN). This was followed by RT-PCR. Tests were done to detect the presence of the virus and serotypes. To obtain a specific fragment that allowed identification of DENV, we used primers forward D1 and reverse D2 in the RT-PCR; these cover a region of the capsid $(C)$ and the premembrane (prM) genes of all DENV serotypes. The expected size of the PCR band was $511 \mathrm{bp}$ indicating the presence of DENV. This was followed by a nested PCR that used the same forward primer (D1) and a pooled suspension of reverse primers, each specific to one DENV serotype. The nested PCR reverse primers were D1 and TS1, TS2, TS3, and TS4. The final reaction volume was $25 \mu \mathrm{l}$, and samples were processed through an initial course of 5 minutes at $94^{\circ} \mathrm{C}, 40$ cycles of 1 minute at $94^{\circ} \mathrm{C}, 60^{\circ} \mathrm{C}$ for 1 minute, and a final extension cycle of $72^{\circ} \mathrm{C}$ during 10 minutes (Lanciotti et al. 1992). The sample was run with four positive reference check strains of DENV1-DENV4 provided by the Regional Research Center "Dr. Hideyo Noguchi", Merida, Yucatan, Mexico. For DEN1 strain H15911P5, DEN2: H17247P4, DEN3: H87, and DEN4: H241, a negative check (PCR reactive), and a molecular marker $\varnothing \times 174$, Haelll Digest (BioLabs) were used. Amplification products were visualized on a $1.5 \%$ agarose gel containing ethidium bromide. A positive result was indicated by the formation of a band during electrophoresis, which was visualized under ultraviolet light; a negative result was demonstrated by no band. A positive result was compared with a marker to determine the size of the base pair. The sizes of the dengue viral base pairs were $490 \mathrm{bp}$ for DEN-1, $230 \mathrm{bp}$ for DEN-2, 320 bp for DEN-3, and 398 bp for DEN-4 (Lanciotti et al. 1992).

Data Analysis. Analysis of variance was used to calculate whether the presence of Aedes mosquitoes by collecting method, i.e., ovitrap and engine back pack aspirator, was statistically different at the five localities (Zar 1999). Tukey's test was used to compare paired arithmetic means among localities and Ae. albopictus/aegypti numbers (SPSS 19.0, SPSS, Chicago, IL).

\section{Results}

Ovitraps. In total, 420 ovitraps were placed at the five sampled localities, although only 409 (97.4\%) were recovered, missing were lost. Eggs on filter paper stripes were found in $358(87.5 \%)$ ovitraps. Most eggs were in traps at R. Sierra $(99 \%)$ while fewest ovitraps $(77.6 \%)$ with eggs were at A. Villalon (Table 1). ANOVA did not show significant differences among the five localities for Aedes mosquitoes $(F=5.953$, df $4, P<0.000)$. In total, 18,571 Aedes eggs were collected from all localities. Most eggs, 8,551, were collected at R. Sierra, followed by Mahuacates with 6,128 . From the 358 ovitraps only $1,965(10.6 \%)$ eggs were successfully reared to adults. Mahuacates was the locality with the most adults, $593(30.2 \%)$, while the food site had only $60(3.1 \%)$. For emerged adults, 1,280 (65.1\%) eggs produced Ae. albopictus mosquitoes, 698 (35.5\%) females and 582 $(29.6 \%)$ males. Most Ae. albopictus, 586 (29.8\%) with $323(16.4 \%)$ females and $263(13.4 \%)$ males, were at Mahuacates. A. Villalon had the fewest Ae. albopictus - $16(0.8 \%)$ of which $14(0.7 \%)$ were females and two $(0.1 \%)$ males. Ae. aegypti were $34.9 \%$ of the emerged mosquitoes. The locality with the most adults reared was A. Villalon, with $301(15.3 \%)$, while Mahuacates had the fewest, only seven $(0.3 \%)$. Of 685 Ae. aegypti total, 320 (16.3\%) were females and $365(18.6 \%)$ males. Most females (143 or $7.3 \%$ ) and males (158 or $8 \%$ ) were at A. Villalon. Ae. albopictus and $A$ e. aegypti were recorded at the five localities. Both species were captured in $31(8.7 \%)$ of the 358 ovitraps. R. Sierra had the most ovitraps with both 


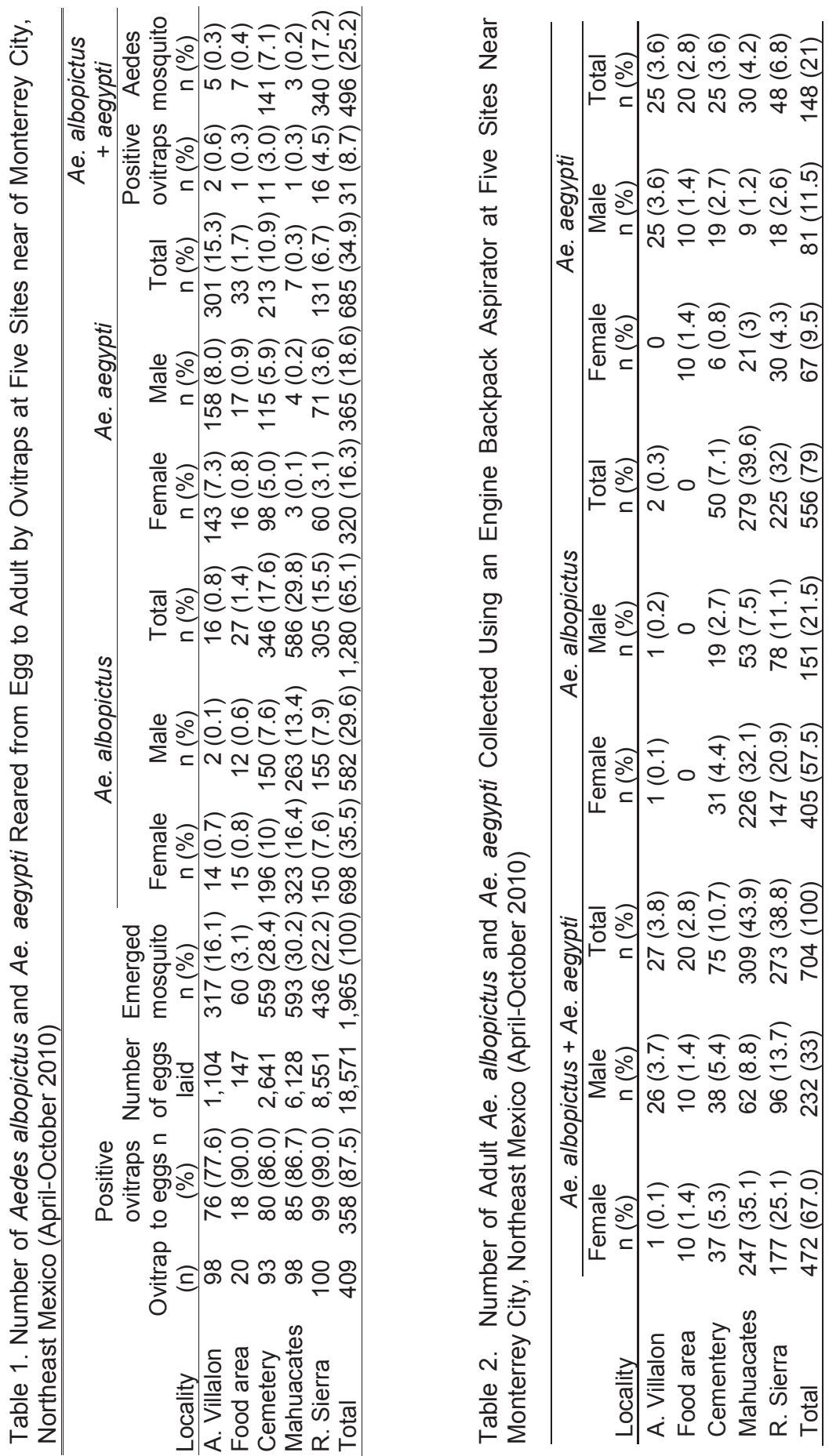


species, $16(4.5 \%)$, whereas only one $(0.3 \%)$ trap each at the food area and Mahuacates had eggs of both species. Adults reared from the 31 ovitraps produced 496 Aedes (25.2\%) mosquitoes. Overall, the ovitrap method was successful in obtaining more Ae. albopictus (65.1\%) than Ae. aegypti (34.9\%). Numbers of emerged adults were similar by sex -- 1,018 (51.8\%) females and $947(48.2 \%)$ males.

Engine Backpack Aspirator. In total, 704 Ae. albopictus and Ae. aegypti were collected using the engine backpack aspirator, divided as 472 (67\%) females and $232(33 \%)$ males (Table 2). Both species shared outdoor premises at the five study localities. Most (309 or 43.9\%) were caught at Mahuacates, while only 20 $(2.8 \%)$ were captured at the food area. The total collected were $556(79 \%) \mathrm{Ae}$. albopictus, 405 (57.5\%) females and 151 (21.5) males. Mahuacates had the most Ae. albopictus, 279 (39.6\%) of which 226 were females $(32.1 \%)$ and $53(7.5 \%)$ males. R. Sierra had 225 (32.0\%) Ae. albopictus, with 147 (20.9\%) females and 78 $(11.1 \%)$ males. No Ae. albopictus was at the food area.

Ae. aegypti collected with the backpack aspirator totaled $148(21 \%)$, of which $67(9.5 \%)$ were females and $81(11.5 \%)$ males. The species was more abundant at R. Sierra (48 or $6.8 \%$ ), while the food area had just $20(2.8 \%)$. Thirty female $(4.3 \%)$ Ae. aegypti were collected at R. Sierra, while more male Ae. aegypti (25 or $3.6 \%$ ) were collected at A. Villalon (Table 2). Results showed the engine backpack aspirator more effective in catching 556 (79\%) Ae. albopictus than 148 (21\%) Ae. aegypti at the five localities. Similarly, we noticed the backpack aspirator captured more female Aedes (67\%) than males (33\%). However, ovitraps were a better method than backpack aspirator to obtain Ae. albopictus and Ae. aegypti at the study sites.

Detection of Dengue Virus. In total, 144 groups of Aedes mosquitoes were processed using RT-PCR. Groups ranged from one to 25 mosquitoes. Sixty-eight adult $A$ e. albopictus emerged from ovitraps, and 35 were captured by the backpack aspirator. Ae. aegypti groups from ovitraps were 32, and nine by the backpack aspirator (Table 3). Only one group of four female Ae. albopictus reared from eggs to adults obtained at Mahuacates was detected by RT-PCR as positive for DENV. Thus, vertical or transovarial transmission of DENV was documented for Ae. albopictus in northeastern Mexico.

Table 3. Female and Male Ae. albopictus and Ae. aegypti Processed by RT-PCR for Dengue Viral RNA from Five Sites near Monterrey City, Northeast Mexico (AprilOctober 2010)

\begin{tabular}{|c|c|c|c|c|c|c|c|c|c|c|c|c|}
\hline \multirow[b]{3}{*}{ Locality } & \multicolumn{6}{|c|}{ Aedes albopictus } & \multicolumn{6}{|c|}{ Aedes aegypti } \\
\hline & \multicolumn{2}{|c|}{ Ovitraps } & \multicolumn{4}{|c|}{ Backpack aspirator } & \multicolumn{2}{|c|}{ Ovitraps } & \multicolumn{4}{|c|}{ Backpack aspirator } \\
\hline & $\begin{array}{l}\text { No. } \\
\text { pools }\end{array}$ & $\begin{array}{c}\text { Mean } \\
\text { pool } \\
\text { size }\end{array}$ & $\begin{array}{c}\text { DENV } \\
\text { positive } \\
\text { pools }\end{array}$ & No. & $\begin{array}{c}\text { Mean } \\
\text { pool } \\
\text { size } \\
\end{array}$ & $\begin{array}{l}\text { DENV } \\
\text { positive } \\
\text { pools }\end{array}$ & $\begin{array}{l}\text { No. } \\
\text { pools }\end{array}$ & $\begin{array}{c}\text { Mean } \\
\text { pool } \\
\text { size }\end{array}$ & $\begin{array}{l}\text { DENV } \\
\text { positiv } \\
\text { pools }\end{array}$ & pools & $\begin{array}{c}\text { Mean } \\
\text { pool } \\
\text { size }\end{array}$ & $\begin{array}{l}\text { DENV } \\
\text { positive } \\
\text { pools }\end{array}$ \\
\hline A.Villalon & 2 & 5.3 & 0 & 2 & 1 & 0 & 13 & 22.3 & 0 & 1 & 25 & 0 \\
\hline Food area & 2 & 13.4 & 0 & 0 & 0 & 0 & 2 & 16.5 & 0 & 2 & 10 & 0 \\
\hline Cementery & 16 & 20.5 & 0 & 4 & 10.8 & 0 & 9 & 23.4 & 0 & 2 & 10.7 & 0 \\
\hline Mahuacates & 30 & 16.7 & 1 & 16 & 12.8 & 0 & 2 & 3.5 & 0 & 2 & 13.7 & 0 \\
\hline R. Sierra & 18 & 15.8 & 0 & 13 & 14.2 & 0 & 6 & 20.8 & 0 & 2 & 23.2 & 0 \\
\hline Total & 68 & & 1 & 35 & & 0 & 32 & & 0 & 9 & & 0 \\
\hline
\end{tabular}


The RNA amplification using primers D1 and D2 showed a band of $511 \mathrm{bp}$ (Fig. 1). However, the second round of amplification with the type-specific primers could not determine the serotype of the group.

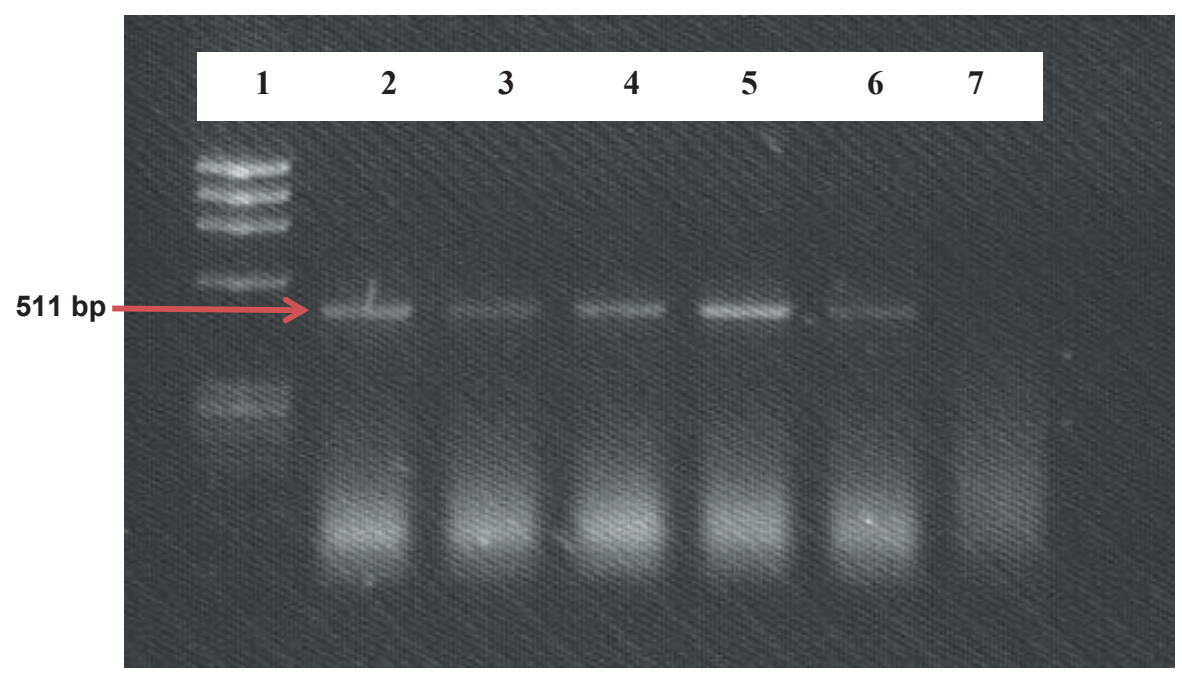

Fig. 1. Amplification by RT-PCR of RNA of Aedes albopictus in an ovitrap group from Mahuacates, near Monterrey City, NE, Mexico. Lane 1: ØX174 molecular size marker (bp), Lanes 2-5: positive reference checks DENV1-DENV4, Lane 6: RNA amplification of Ae. albopictus from Santiago, NL, Mexico, Lane 7: negative check (PCR reactives).

\section{Discussion}

We reported in this research the role of Ae. albopictus as a potential vector of DENV through transovarial infection by females reared to adults from eggs collected in ovitraps in Mexico. Ae. aegypti and Ae. albopictus overlapped in the sampled area where dengue occurs year to year. Although RT-PCR and Lanciotti primers were not able to determine DENV serotypes under laboratory conditions, the epidemiological scenario with active dengue transmission at the study localities suggested an Ae. albopictus vector. Mosquitoes caught outdoors were separated into 103 groups of Ae. albopictus and $41 \mathrm{Ae}$. aegypti. In the 144 groups, only one of four female Ae. albopictus was naturally infected with DENV at Mahuacates, near Monterrey City, Northeast Mexico, in summer 2010. Ae. albopictus was more susceptible than Ae. aegypti to infection by DENV (Lambrechts et al. 2010) and dominant at this locality. The group was positive for DENV but the serotype of dengue was not determined by our experiment. This method with high sensitivity and specificity is reported to be useful for rapidly detecting dengue virus in its vector. Vertical transmission of dengue virus has been reported in Aedes vectors elsewhere. Several surveillance studies suggested vertical transmission occurs at a low rate (Akbar et al. 2008). Numerous factors affect detection of dengue viruses in 
mosquitoes, including sensitivity of the testing methodologies, proper techniques for sampling, as well as proper handling of samples (Lambrechts et al. 2010). The positive group was obtained in summer 2010, which is consistent with studies that found more transovarial transmission of dengue during the summer (Angel and Joshi 2008, Lambrechts et al. 2010).

$A e$. albopictus and $A e$. aegypti develop in artificial containers and can be common in almost all areas. Often Ae. albopictus displaces Ae. aegypti in suburban and rural areas, whereas $A e$. aegypti is dominant in urban environments (O'Meara et al. 1995). Ae. albopictus and Ae. aegypti were found at the five localities in this study. The five localities were on the outskirts of cities, which is consistent with the biology of Ae. albopictus. This is a tree-hole mosquito, and their breeding places in nature are small, restricted, shaded bodies of water surrounded by vegetation. It inhabits densely vegetated rural areas. However, ecological flexibility allows it to colonize many man-made sites and urban regions. It may reproduce in man-made containers. Establishment and survival of Ae. albopictus in non-urbanized areas increase public health concerns for rural areas (Eritja et al. 2005).

Transovarial transmission of DENV has been reported in Aedes mosquitoes in endemic countries. Natural dengue transmission has been studied. However, in Mexico Ae. albopictus is not as studied as Ae. aegypti. The finding from this research is consistent with the results of Ibanez-Bernal et al. (1997) who found Ae. albopictus naturally infected with dengue at Reynosa, Mexico, the first record in America. Ae. albopictus was the vector responsible for the 2001 outbreak in Hawaii (Effler et al. 2005), but Ae. albopictus is considered an inefficient vector of epidemic dengue because it is less anthropophilic and not as well adapted as Ae. aegypti to urban domestic environments (Gubler and Kuno 1997).

In conclusion, this study suggested that vertical transmission was occurring at Mahuacates, maintaining the virus in nature until outbreak season. Also, mosquitoes could be acting as reservoirs of dengue virus. It is important to continue this investigation because more information on Ae. albopictus in nature is needed. We used molecular methods to detect the virus in the vector, which could be used for a molecular vector surveillance system to monitor the virus in Ae. albopictus and warn of risk of early onset of disease in unaffected areas.

\section{Acknowledgment}

This research was financially supported by Mexico CONACYT Grant FONSALUD-2010-01-141768.

\section{References Cited}

Akbar, M. R., R. Agoes, T. Djatie, and S. Kodyat. 2008. PCR detection of dengue transovarial transmissibility in Aedes aegypti in Bandung, Indonesia. Proc. ASEAN Congr. Trop. Med. Parasitol. 3: 84-89.

Angel, M. R., and V. Joshi. 2008. Distribution and seasonality of vertically transmitted dengue viruses in Aedes mosquitoes in arid and semi-arid areas of Rajashtan, India. J. Vector Borne Dis. 45: 56-59.

Casas-Martinez, M., and J. L. Torres-Estrada. 2003. First evidence of Aedes albopictus (Skuse) in Southern Chiapas, Mexico. Emerg. Infect. Dis. 9: 606607. 
CDC (Centers for Disease Control and Prevention). 1986. Aedes albopictus introduction in Texas. MMWR 35: 41-142.

CDC (Centers for Disease Control and Prevention). 2011. Largest Dengue Outbreak in Puerto Rico History. http://www.cdc.gov/dengue/dengue_upd/ resources/DengueUpdateVo3No1.pdf

Clark, G., and D. J. Gubler. 1994. Use of the CDC backpack aspirator for surveillance of Aedes aegypti in San Juan, Puerto Rico. J. Am. Mosq. Control Assoc. 10: 119-124.

Darsie, R. F., and R. A. Ward. 2005. Identification and Geographical Distribution of the Mosquitoes of North America, North of Mexico. University Press of Florida, Gainesville, FL.

Effler, P. V., L. Pang, P. Kitsutani, et al. 2005. Dengue fever, Hawaii, 2001-2002. Emerg. Infect. Dis. 11: 42-749.

Eritja, R., R. Escosa, J. Lucientes, E. Marqus, R. Molina, D. Roiz, S. Ruiz. 2005. Worldwide invasion of vector mosquitoes: present European distribution and challenges for Spain. Biological Invasions 7: 87-97.

Garcia-Rejon, J., M. A. Loroño-Pino, J. A. Farfan-Ale, L. Flores-Flores, E.P. Rosado-Paredes, N. Rivero-Cardenas R. Najera-Vazquez, S. Gomez-Carro, V. Lira-Zumbardo, P. Gonzalez-Martinez, S. Lozano-Fuentes, D. ElizondoQuiroga, B.J. Beaty and L. Eisen.. 2008. Dengue virus-infected Aedes aegypti in the home environment. Am. J. Trop. Med. Hyg. 79: 940-950.

Gubler, D. J. 1988. Dengue, pp. 223-260. In T. P. M. Monath [ed.], Epidemiology of Arthropod-borne Viral Disease. CRC Press, Boca Raton, FL.

Gubler, D. J., and G. Kuno. 1997. Dengue and dengue hemorrhagic fever, pp. 6188. CAB International, New York.

Hawley, A. H. 1988. The biology of Aedes albopictus. J. Am. Mosq. Control Assoc. 1: 1-39.

Ibañez-Bernal, S., and C. Martínez-Campos. 1994. Aedes albopictus in México. J. Am. Mosq. Control Assoc. 10: 231-232.

Ibañez-Bernal, S., B. Briseño, J. P. Mutebi, et al. 1997. First record of Aedes albopictus naturally infected with dengue virus during the 1995 outbreak at Reynosa, Mexico. Med. Vet. Entomol. 11: 305-309.

INEGI. 2010. Censo de Población y Vivienda. http://www.inegi.org.mx/sistemas/ mexicocifras/default.aspx?ent $=19 \&$ mun $=049 \& s r c=487$

Lambrechets, L., T. W. Scott, and D. J. Gubler. 2010. Consequences of the expanding global distribution of Aedes albopictus for dengue virus transmission. Plos. Negl. Trop. Dis. 4(5) e646.

Lanciotti, R. S., C. H. Calissher, D. J. Gubler, et al. 1992. Rapid detection and typing of dengue viruses from clinical samples by using reverse transcriptase-polymerase chain reaction. J. Clin. Microbiol. 30: 545-551.

Mitchell, C. J., and B. R. Miller. 1990. Vertical transmission of dengue viruses by strains of Aedes albopictus recently introduced into Brazil. J. Am. Mosq. Control Assoc. 6: 251-253

MMWR. 2010. Locally acquired Dengue-Key West, Florida, 2009-2010. Mortality and Morbidity Weekly Report. Center For Disease Control and Prevention. 59 (19):577-581.

O'Meara, G. F., G. Evans, Jr., and J. P. Cuda. 1995. Spread of Aedes albopictus and decline of Ae. aegypti (Diptera: Culicidae) in Florida. J. Med. Entomol. 32: 554-562. 
Orta-Pesina, H., R. Mercado-Hernandez, and M. A. Valdez-Rodriguez. 2001. Aedes albopictus in Allende City, Nuevo Leon, Mexico. J. Am. Mosq. Control Assoc. 17: 260-261.

Orta-Pesina, H., R. Mercado-Hernandez, and J. F. Elizondo-Leal. 2005. Distribucion de Aedes albopictus (Skuse) en Nuevo Leon, Mexico, 20012004. Salud Pública de México 47: 163-165.

Pérez, O., J. Rodríguez, J. A. Bisset, et al. 2004. Manual de Indicaciones Técnicas para Insectarios. Ciudad de La Habana, Editorial Ciencias Médicas.

Prontuario de Información Geográfica Municipal de los Estados Unidos Mexicanos. Santiago, Nuevo León. 2009. Clave geoestadística: 19049.

Prontuario de Información Geográfica Municipal de los Estados Unidos Mexicanos. Guadalupe, Nuevo León. 2009. Clave geoestadística: 19026.

Rodríguez-Tovar, M. L., and M. G. Ortega-Martínez. 1994. Aedes albopictus in Muzquiz City, Coahuila, México. J. Am. Mosq. Control Assoc. 10: 587.

Rosen, L. 1988. Further observations on the mechanism of vertical transmission of flaviviruses by Aedes mosquitoes. Am. J. Trop. Med. Hyg. 39: 123-126.

Rosen, L., L. E. Roseboom, D. J. Gubler, et al. 1985. Comparative susceptibility of mosquito species and strains to oral and parenteral infection with dengue and Japanese encephalitis viruses. Am. J. Trop. Med. Hyg. 34: 603-615.

Rudnick, A., and Y. C. Chan. 1965. Dengue type 2 virus in naturally infected Aedes albopictus mosquitoes in Singapore. Science 149: 638-639.

Salomón-Grajales, J., G. V. Lugo-Moguel, V. R. Tinal-Gordillo, et al. 2012. Aedes albopictus mosquitoes, Yucatan Peninsula, Mexico. Emerg. Infect. Dis. 18: 525-527.

Siler, J. F., M. W. Hall, and A. P. Hitchens. 1926. Dengue: its history, epidemiology, mechanism of transmission, etiology, clinical manifestations, immunity, and prevention. Philipp J. Sci. 29: 1-304.

Skuse, F. A. 1894. The banded mosquito of Bengal. Indian Mus. Notes 30: 20.

SSA (Secretaría de Salud). 2012. http://www.ssaver.gob.mx/Servicios_de_Salud/ BoletinEpidem/Boletines/2000-26/page17.html

WHO (World Health Organization). 2009. Dengue: Guidelines for Diagnosis, Treatment, Prevention and Control. New Edition. Geneva.

Zar, J. H. 1999. Biostatistal Analysis. $4^{\text {th }}$ ed. Prentice Hall, Northern Illinois, 